\title{
The Perfection of Financial Subsidies for Urban and Rural Basic Endowment Insurance: Based on Research in Guangdong Province
}

\author{
Yini Chen \\ College of Economics, Jinan University, Guangzhou, China \\ Email: chenyn0902@163.com
}

How to cite this paper: Chen, Y.N. (2020) The Perfection of Financial Subsidies for Urban and Rural Basic Endowment Insurance: Based on Research in Guangdong Province. Modern Economy, 11, 140-154. https://doi.org/10.4236/me.2020.111013

Received: December 9, 2019

Accepted: January 14, 2020

Published: January 17, 2020

Copyright $\odot 2020$ by author(s) and Scientific Research Publishing Inc. This work is licensed under the Creative Commons Attribution International License (CC BY 4.0).

http://creativecommons.org/licenses/by/4.0/

\begin{abstract}
The social security relies on public finance. However, the benefits of urban and rural basic endowment insurance in China have been at a low level since the establishment in 2014. This article explores the possibility of improving pension based on the view of public finance. By analyzing the status and fiscal subsidy policies of urban and rural basic endowment insurance in Guangdong province, the passage found that the fund supported endowment insurance for public finance was not a burden. Then, the ELES was used in the essay to estimate an appropriate level of pension based on the needs of the elderly and funding required could be afforded by public finance. Finally, it proposes some ways to optimize financial subsidies.
\end{abstract}

\section{Keywords}

Urban and Rural Basic Endowment Insurance, Fiscal Subsidies, An Appropriate Level of Pension

\section{Introduction}

The problem of population aging is a common challenge facing countries in the 21 st century. According to the internationally accepted view, the proportion of the population aged 60 or over in the country or region reached $10 \%$, or the proportion of the population aged 65 or over reached 7\%, that is, into aging. According to this standard, China has entered an aging society in 2000. However, China is still in the primary stage of socialism. The acceleration of population aging and the lagging of the construction of the endowment insurance system will inevitably pose huge hidden dangers to sustainable economic development and social stability and solidarity. Different from the inclusive pension insurance 
system of most developed countries in the world, China's social pension insurance system is divided into basic endowment insurance for urban employees, endowment insurance for institutions and public institutions, and basic endowment insurance for urban and rural residents (hereinafter referred to as "UREI"). The first two types of endowment insurance systems have a long history and relatively high levels of protection, but the UREI is still in its infancy.

In 2014, the State Council issued the Opinions on Establishing a Unified Basic Endowment Insurance System for Urban and Rural Residents, combining the new rural endowment insurance established in 2009 and the urban endowment social endowment insurance established in 2011 into a basic endowment insurance for urban and rural residents, the target groups are mainly rural residents and urban residents who do not meet the conditions for employees' basic endowment insurance. At present, the participant of UREI has reached 26.26 million in Guangdong Province, basically covering the whole population [1]. The biggest highlight of UREI is the basic pension paid by the government in full. The minimum standard for basic pensions has increased year by year in Guangdong Province since 2012. After six years of adjustments, it has increased from 55 yuan to 148 yuan per person per month in 2018, which is 60 yuan higher than the national basic pension standard. The basic pension constitutes a major part of the benefits of UREI. However, the minimum standard of basic pension stipulated by Guangdong Province cannot obviously guarantee the basic life of elderly residents. Social security fund comes from public finance and it is the trend to increase financial subsidies of UREI to improve the lives of older people. This article will analyze the financial subsidy policies and treatment levels of UREI in Guangdong Province, and further explore the possibility of increasing fiscal subsidies and optimize the fiscal policies of UREI.

\section{Literature Review}

Regarding the financial subsidies of UREI, the academic community mainly discusses such issues as the appropriate pension, financial responsibility, and financial affordability. Xiumei Li, Chunlin Yao and Meizhi Duan believe that the financial subsidy for UREI should reach three levels of goals, namely, to encourage residents to participate in insurance, to encourage residents to increase their contribution levels, and to improve the level of residents' protection. The current financial subsidy is far from achieving the goal of "basic insurance" [2]. It is a real fact that the level of pension insurance is low and pension gold treatment needs to be improved. How to determine the moderate pension benefits? Scholars have done a lot of research on this. Lijian Wang and Xiaogang Ye [3], Zhonghai Liu, Lianyou Li and Minyan Peng [4], Shu Bian, Yana Sun and Ningxian LI [5], Peng Jing, Mingjun Chen and Qiuming $\mathrm{Hu}$ [6] have used the extended linear expenditure model (ELES) to separate basic consumption expenditures from total consumption expenditure as a modest level of pensions. Li Huang set the target pension replacement rate of UREI to $50 \%$ of the net income 
of rural residents per capita with reference to employee endowment insurance [7]. Yi Shen believed that the lower limit of modest levels of pensions should meet the basic survival of urban and rural residents based on Engel coefficient standard [8].

Regarding the government's responsibility for endowment insurance, scholars have researched from various aspects. Changfeng Shang discussed the necessity of the government to participate in the construction of a rural social endowment insurance system from the aspects of asymmetric information in the private insurance market, narrowing the income distribution gap, the principle of equal benefits, and compensation to farmers [9]. Changyuan Li believes that the lack of government financial responsibility restricts the development of rural social endowment insurance in China, and the government's financial responsibility should be clarified [10]. Mengjie Long studied the relationship between collective subsidies and the participation rate of farmers, and believed that the strengthening of government responsibility is conducive to increasing the enthusiasm of farmers for participating in insurance [11]. Xiaoxia Gong believes that the public product nature of rural social endowment insurance requires government finances to give certain financial support [12]. Bin Yang used the amount of fiscal subsidy as an indicator of total government fiscal responsibility, selected 2013 population data, and used the extreme difference, extreme value ratio, standard deviation, and coefficient of variation to measure the difference, and found significant differences in local government financial responsibility for UREI, mainly due to the large difference in the number of insured persons in different regions and the difference in the subsidy methods of the central government to different regions [13].

To improve the basic old-age insurance benefits for urban and rural residents, the government is bound to increase capital investment. Is the finance able to afford it? Calculating from the national level, Peng Jing, Mingjun Chen and Qiuming $\mathrm{Hu}$ found that if the basic pension replacement rate was increased to $30.5 \%$ and the subsidy was given at $27.3 \%$ of the individual payment base, the finance could bear it [6]. Huoyun Zhu [14], Li Huang, Feng Luo and Hongmei Liu [15], Qiong Li and Yong Li [16] selected relevant data from Wenzhou City, Guangdong Province, and Hunan Provinces for research. They believed that the overall burden of financial subsidies for endowment insurance is relatively light and there is room for improvement, but there are significant differences in county financial affordability. In summary, scholars have studied UREI from various aspects. They basically reached a consensus that the current financial subsidy for UREI is low, and public finance has the ability to improve pension benefits. However, Scholars are still divided on the extent to which level of UREI benefits should reach. In reality, the modest treatment of urban and rural residents' endowment insurance in different provinces will vary due to different economic development and price levels, and there will be differences in fiscal subsidy policies for UREI due to different financial strength and population size. 
This article will conduct a detailed analysis of Guangdong Province.

\section{Financial Subsidy Status of UREI in Guangdong Province}

\subsection{Fiscal Subsidy Policies of UREI in Guangdong Province}

The benefits of UREI consist of a basic pension and a personal account pension, paid for life. The basic pension is paid in full by the government. The personal account pension is calculated by referring to the employee pension insurance. It is obtained by dividing the personal account storage amount by the number of months. The personal account storage amount mainly comes from individual contributions and the government will give certain financial subsidies by different payment standards. Guangdong Provincial People's Government issued a notification on the revision of "urban and rural residents social pension insurance implementation of the Guangdong Provincial Measures" (hereinafter referred to as "Implementation Measures") in July 2014. Therefore, financial subsidies from all levels of government to the basic pension and individual account pension are illustrated. The basic pension is borne by the central, provincial, city, and county levels of finance. Taking 2014 year as an example, the central pension standard set by the central government is 55 yuan per person per month. The central government subsidizes Guangdong Province at $50 \%$ of this standard (that is, 27.5 yuan per person per month). The basic pension standards identified in Guangdong Province is 65 Yuan/person-month, then the rest of the funds (37.5 million), which are afford by city and county (cities, districts) finance in the Pearl River Delta area. While, provincial finance should afford $1 / 2$ of the rest (that is, 18.75 per person per month per month) in the west, east and north Guangdong, and the other $1 / 2$ of the rest are afford by city and county (cities, districts) finance.

The "Implementation Measures" stipulates that each region can raise the standard of basic pension according to the actual situation, but the increased funds must be responsible for each region. Except for Guangzhou and Zhuhai, which have their own payment levels and subsidy standards based on the conditions of this city, the rest of the prefecture-level cities made the same provisions with the "Implementation Measures" that issued by Provincial People's Government.

As shown in Table 1, Guangzhou and Zhuhai have streamlined their payment levels and increased their payment subsidies on the basis of the Guangdong Province's Implementation Measures. Moreover, Zhuhai City has transformed the fixed subsidy method into a proportional subsidy method, which is a very worthwhile practice.

\subsection{The Pension Levels of UREI in Guangdong Province}

Table 2 shows the basic pension standards and actual benefits of UREI in some cities of Guangdong Province from 2014 to 2017. From the perspective of the whole province, the urban-rural endowment insurance benefits in the Pearl River 
Table 1. Fiscal subsidy policies of UREI in Guangdong province.

\begin{tabular}{|c|c|c|c|}
\hline Area & $\begin{array}{l}\text { Personal payment standard } \\
\quad \text { (yuan/person year) }\end{array}$ & $\begin{array}{l}\text { Financial contribution subsidy } \\
\text { (yuan/person year) }\end{array}$ & Note \\
\hline \multirow[t]{10}{*}{ Province } & 120 & not less than 30 & \multirow{10}{*}{$\begin{array}{l}\text { The required funds are borne by the } \\
\text { municipal and county (city, district) } \\
\text { finances in the Pearl River Delta region; } \\
\text { the eastern, western and northern } \\
\text { regions of Guangdong are arranged by } \\
\text { the provincial finance at the rate of } 1 / 3 \text { of } \\
\text { the minimum subsidy mentioned above, } \\
\text { and the rest are financed by the city, } \\
\text { county (city, district) finances each bears } \\
\text { half. Conditional areas can appropriately } \\
\text { increase payment subsidies, and the } \\
\text { increased funds are responsible for their } \\
\text { own responsibility. }\end{array}$} \\
\hline & 240 & & \\
\hline & 360 & & \\
\hline & 480 & not less than 60 & \\
\hline & 600 & & \\
\hline & 960 & & \\
\hline & 1200 & & \\
\hline & 1800 & & \\
\hline & 2400 & & \\
\hline & 3600 & & \\
\hline \multirow[t]{7}{*}{ Guangzhou } & 120 & 180 & \\
\hline & 360 & 420 & \\
\hline & 600 & 600 & \\
\hline & 840 & 720 & \\
\hline & 1080 & 840 & \\
\hline & 1320 & 900 & \\
\hline & 1560 & 960 & \\
\hline \multirow[t]{3}{*}{ Zhuhai } & 720 & 468 & \multirow{3}{*}{$\begin{array}{l}\text { The subsidy is based on } 65 \% \text { of the } \\
\text { individual's contribution }\end{array}$} \\
\hline & 1200 & 780 & \\
\hline & 1440 & 936 & \\
\hline
\end{tabular}

Source: Based on Yue Fu [2014] No. 37, Sui Fu Ban [2014] No. 66 and bead Government [2014] No. 88 documents gathered from.

Table 2. Pension levels of various cities in Guangdong Province, 2014-2017.

(Unit: Yuan/person·month)

\begin{tabular}{|c|c|c|c|c|c|c|c|c|}
\hline \multirow{2}{*}{$\begin{array}{l}\text { Years } \\
\text { Area }\end{array}$} & \multicolumn{2}{|c|}{2014} & \multicolumn{2}{|c|}{2015} & \multicolumn{2}{|c|}{2016} & \multicolumn{2}{|c|}{2017} \\
\hline & $\begin{array}{c}\text { Basic pension } \\
\text { standards }\end{array}$ & $\begin{array}{l}\text { Annual average } \\
\text { pension benefits }\end{array}$ & $\begin{array}{c}\text { Basic pension } \\
\text { standards }\end{array}$ & $\begin{array}{l}\text { Annual average } \\
\text { pension benefits }\end{array}$ & $\begin{array}{c}\text { Basic pension } \\
\text { standards }\end{array}$ & $\begin{array}{l}\text { Annual average } \\
\text { pension benefits }\end{array}$ & $\begin{array}{c}\text { Basic pension } \\
\text { standards }\end{array}$ & $\begin{array}{l}\text { Annual average } \\
\text { pension benefits }\end{array}$ \\
\hline Province & 95 & 125.13 & 100 & 141.65 & 110 & 148.41 & 120 & 156 \\
\hline Guangzhou & 165 & 574 & 180 & 608 & 191 & 624 & 202 & 633 \\
\hline Zhuhai & 330 & 453 & 350 & 475 & 360 & 490 & 380 & 520 \\
\hline Foshan & 135 & 127.50 & 155 & 262.12 & 170 & 277 & 180 & 288.33 \\
\hline Zhongshan & 80 & 72.5 & 100 & 97.5 & 110 & 115.92 & 120 & 129.19 \\
\hline Huizhou & 105 & & 125 & 165 & 135 & 173 & 145 & 280 \\
\hline Jiangmen & 95 & 70.28 & 100 & 106.94 & 100 & 121.06 & 120 & 132.73 \\
\hline Shantou & 95 & 80 & 100 & 114 & 110 & 117.79 & 119.65 & 122.96 \\
\hline Zhanjiang & 80 & 77.90 & 100 & 111.61 & 110 & 115.54 & 120 & 123.22 \\
\hline Heyuan & & & & & 110 & 104.4 & 120 & 120.92 \\
\hline Yunfu & 95 & 74.55 & 100 & 94.98 & & & & \\
\hline
\end{tabular}

Data source: Compiled from the website of the Human Resources and Social Affairs Department of Guangdong Province and other prefecture-level cities. 
Delta region are generally higher than those in the eastern, western and northern regions of Guangdong. The basic pension standards of the Pearl River Delta region are basically higher than the minimum standards set by the province, and the actual benefits enjoyed by elderly residents are basically higher than the provincial average level. The level of pensions at the cities in the eastern, western and northern regions of Guangdong is comparable. In these cities, the basic pension standards are consistent with the minimum standards set by the province, and the actual pension benefits are generally lower than the provincial average. On the other hand, the level of pensions in the Pearl River Delta region has clearly formed three levels. Guangzhou and Zhuhai are far ahead of the provincial average level in terms of basic pensions and actual benefits. The pension standard in Zhuhai has always ranked first in the province, almost twice that of Guangzhou, more than three times the minimum standard set by the province. Nevertheless, the elderly in Guangzhou enjoy the highest benefits, which is more than 100 yuan higher than Zhuhai. The pension in Huizhou is slightly higher than the provincial average, and which in Foshan is basically more than half of the provincial average. And the pension levels of Zhongshan and Jiangmen are almost the same as those of cities in eastern, western and northern Guangdong. Based on the view of basic pension, taking the standard set by province as an example, it increased by 5 yuan, 10 yuan and 10 yuan from 2014 to 2017. Moreover, the rate of increase is very low, and no clear pattern.

In general, pension levels in Guangdong provinces are very different. The pension level in the Pearl River Delta region is generally higher than that in the eastern, western and northern regions of Guangdong. The pension level in the Pearl River Delta region is extremely uneven. Which in Guangzhou and Zhuhai are much higher than other cities? In addition, the province's basic pension lacks a normal adjustment mechanism. Although it has been increasing year by year, the increase rate is relatively low. The government's financial subsidy is an important source of funding for urban-rural endowment insurance. The disparity in pension benefits among prefecture-level cities is mainly caused by differences in fiscal subsidy policies. It can be seen from Table 1 and Table 2 that the benefits of UREI in Guangzhou and Zhuhai are far ahead of the provincial average. First, the two cities have higher basic pensions, and second, the governments of the two cities pay more for individual contributions. Higher subsidies have increased the amount of savings in personal accounts. According to the "Implementation Measures", the provincial finance of Guangdong Province does not provide any subsidies for the basic pensions and personal contributions in the Pearl River Delta region, and it is entirely borne by the municipal and county financial system. The measures ignore the fact that the economic development of the prefecture-level cities in the Pearl River Delta region is not balanced, and the financial resources are very different. For example, due to the weak financial strength of Zhongshan and Jiangmen, the benefits of UREI are relatively low in the Pearl River Delta region, and they are almost inferior to those in the eastern, 
western and northern regions of Guangdong. The provincial finances will give some subsidies to basic pensions and personal contributions in the eastern, western and northern regions of Guangdong, but the subsidy standards are low, and the funds needed to raise basic pensions and personal contribution subsidies by cities are all borne by the municipal finances, so these cities have chosen the minimum subsidy standards set by the province.

There are obvious differences on the urban-rural residential security benefits in various regions of Guangdong Province. The level of pensions in most prefecture-level cities obviously cannot guarantee the basic living of elderly residents. What kind of treatment level is appropriate, increasing treatment and increasing financial subsidies will give how much burden to the finance? Next section will build a model and analyze it.

\section{The Possibility of Increasing Fiscal Subsidies for UREI in Guangdong Province}

\subsection{Construction of Extended Linear Expenditure Model}

In 2014, the Opinions of the State Council on Establishing a Unified Basic Endowment Insurance System for Urban and Rural Residents was issued, which explicitly mentioned that the basic endowment insurance system for urban and rural residents should follow the principle of "basic insurance" and give full play to the importance role of social insurance to guarantee the basic life of people. The basic living needs of the elderly are the modest level of UREI benefit. This article draws on a general method for measuring basic living needs in the existing literature-the extended linear expenditure model to measure the appropriateness of UREI benefit in Guangdong from 2014 to 2017. The Extended Linear Expenditure Model (ELES) is a demand function system derived by British economist Lunch in 1973. The model assumes that a person's consumption of various goods or services at a certain period depends on his income and the price of the goods. And people's consumption expenditure is divided into basic living needs expenditure and demand expenditures beyond basic living needs, and the model believes that basic living needs are not affected by income, and people meet basic living needs according to a certain marginal consumption tendency. The remaining income is allocated to the expenditure of various commodities, so the basic demand for each commodity can be separated from the actual consumption expenditure. The ELES model expression is:

$$
P_{i} Q_{i}=P_{i} R_{i}+b_{i}\left(Y-\sum_{i=1}^{n} P_{i} R_{i}\right)
$$

Among them, $P_{i} Q_{i}$ is the consumption expenditure of category $i$ goods, $P_{i}$ is the price of category $i$ goods, $Q_{i}$ is the actual consumption of category $i$ goods, $R_{i}$ is the consumption quantity of category $i$ goods meeting basic living needs, and $Y$ is disposable Income, $b_{i}$ represents the marginal consumption propensity of category $i$ goods. The original expression can be written as: 


$$
P_{i} Q_{i}=\left(P_{i} R_{i}-b_{i} \sum_{i=1}^{n} P_{i} R_{i}\right)+b_{i} Y
$$

Define $a_{i}=P_{i} R_{i}-b_{i} \sum_{i=1}^{n} P_{i} R_{i}$ as Equation (1), then $P_{i} Q_{i}=a_{i}+b_{i} Y$ as Equation (2); both sides of Equation (1) sum up $n$ types of goods at the same time to obtain the sum of the basic consumption expenditure of residents for $n$ types of goods $\sum_{i=1}^{n} P_{i} R_{i}=\sum_{i=1}^{n} a_{i} /\left(1-\sum_{i=1}^{n} b_{i}\right)$; then, the basic consumption expenditure of the residents on the goods of the $i$ category can be expressed as: $P_{i} R_{i}=a_{i}+b_{i} \sum_{i=1}^{n} a_{i} /\left(1-\sum_{i=1}^{n} b_{i}\right)$ (3). According to Equation (2), using the OLS method, parameters $a_{i}$ and $b_{i}$ can be estimated, and then substituted into Equation (3), the basic demand of residents for each type of goods can be obtained.

\subsection{Data Collection and Modest Level Calculation}

This article selects rural residents' eight major commodity consumption expenditure data in the "Guangdong Statistical Yearbook" to calculate the appropriate level UREI benefits in Guangdong Province. There are three reasons: First, there is no individual and age difference in basic living needs. In old age, they will continue to choose commodities when they are young [6]; second, conditional urban residents will choose to participate in urban employee endowment insurance. Urban residents participating in UREI are low-income people without fixed income. Their consumption level is close to that of rural residents. Third, there are currently more than 500 million people participating in the UREI nationwide, and rural residents account for more than 95\% [17]. Therefore, in this article, it is reasonable to assume that the basic consumption expenditure of rural residents is equivalent to a moderate pension for older participant of the UREI.

In the "Guangdong Statistical Yearbook", rural residents are divided into five equal parts according to income. Consumption expenditure includes eight items: food, clothing, housing, daily necessities and services, transportation and communications, education, culture and entertainment, medical care, and other supplies and services. The modest treatment for urban and rural residents is a pension treatment that meets the basic living needs of the elderly. It should be an interval value, not too low or too high [18]. Based on the relevant studies, this paper regards the basic consumption expenditure for food as the lower limit of appropriate treatment, and the sum of the basic consumption expenditure for food and clothing as the upper limit of appropriate treatment. According to the relevant data of Guangdong Statistical Yearbook 2014-2017, using SPSS software and OLS method to estimate the parameters $a_{i}$ and $b_{i}$, the regression results show that the model has a good overall fit, all the parameters $b_{i}$ are significant, and the parameters $a_{i}$ of the individual regression equations are not significant. This paper draws on the method used by Zhonghai Liu in the study to modify 
the regression equation that fails the test. The parameter estimation results are shown in Table 3.

According to the parameter estimation results in Table 3, the upper and lower limits of the modest level of UREI benefits in Guangdong Province from 2014 to 2017 can be calculated. At the same time, the actual benefits of UREI in recent years are sorted out and shown in Table 4. The moderate level of UREI benefit increased year by year in Guangdong Province. The lower limit of the appropriate treatment increased from 251.67 yuan per person per month in 2014 to 374.92 yuan per person per month in 2017, and the upper limit of the appropriate treatment raised from 544.08 yuan per person per month in 2014 to 907.42 yuan per person per month in 2017. The actual benefits for urban and rural residents in Guangdong have also increased year by year, from 125.13 yuan per person per month in 2014 to 156 yuan per person per month in 2017. The horizontal comparison between the modest level of UREI benefits and the province's actual level of treatment found that the actual level of treatment was far below the lower

Table 3. Estimation results of ELES model for rural residents in Guangdong Province, 2014-2017.

\begin{tabular}{|c|c|c|c|c|c|c|c|c|c|}
\hline Years & Parameter & Food & Clothes & Live & $\begin{array}{l}\text { Daily necessities } \\
\text { and services }\end{array}$ & $\begin{array}{c}\text { Traffic } \\
\text { communication }\end{array}$ & $\begin{array}{l}\text { Education, culture } \\
\text { and Entertainment }\end{array}$ & $\begin{array}{l}\text { Medical } \\
\text { insurance }\end{array}$ & $\begin{array}{l}\text { Other supplies } \\
\text { and services }\end{array}$ \\
\hline \multirow[t]{3}{*}{2014} & $a_{i}$ & 1929.525 & 0 & 0 & 111.478 & -170.625 & 763.48 & 190.622 & 100.643 \\
\hline & $b_{i}$ & 0.167 & 0.026 & 0.151 & 0.04 & 0.1 & 0.017 & 0.04 & 0.011 \\
\hline & $R^{2}$ & 0.99 & 0.981 & 0.965 & 0.99 & 0.998 & 0.732 & 0.961 & 0.994 \\
\hline \multirow[t]{3}{*}{2015} & $a_{i}$ & 2276.174 & 92.429 & 1013.769 & 236.131 & 0 & 635.788 & 294.195 & 75.15 \\
\hline & $b_{i}$ & 0.167 & 0.021 & 0.111 & 0.031 & 0.09 & 0.024 & 0.032 & 0.012 \\
\hline & $R^{2}$ & 0.993 & 0.981 & 0.98 & 0.974 & 0.955 & 0.817 & 0.963 & 0.95 \\
\hline \multirow[t]{3}{*}{2016} & $a_{i}$ & 2743.126 & 127.933 & 1421.485 & 177.445 & 0 & 567.404 & 352.205 & 76.058 \\
\hline & $b_{i}$ & 0.156 & 0.02 & 0.093 & 0.037 & 0.095 & 0.035 & 0.031 & 0.014 \\
\hline & $R^{2}$ & 0.975 & 0.988 & 0.982 & 0.993 & 0.967 & 0.768 & 0.891 & 0.924 \\
\hline \multirow[t]{3}{*}{2017} & $a_{i}$ & 2680.291 & 136.271 & 1500.394 & 235.241 & 0 & 757.409 & 472.743 & 0 \\
\hline & $b_{i}$ & 0.167 & 0.021 & 0.089 & 0.031 & 0.093 & 0.027 & 0.028 & 0.013 \\
\hline & $R^{2}$ & 0.986 & 0.987 & 0.967 & 0.991 & 0.979 & 0.856 & 0.891 & 0.932 \\
\hline
\end{tabular}

Note: Calculated based on the relevant data of Guangdong Statistical Yearbook 2015-2018.

Table 4. The moderate pensions of UREI in Guangdong Province, 2014-2017.

\begin{tabular}{cccc} 
& & & (Unit: Yuan/person·month) \\
\hline Years & The lower limit & The upper limit & Real pension \\
\hline 2014 & 251.67 & 544.08 & 125.13 \\
2015 & 315.33 & 752.58 & 141.65 \\
2016 & 365.50 & 877.58 & 148.41 \\
2017 & 374.92 & 907.42 & 156.00 \\
\hline
\end{tabular}


limit of the level of modest benefits, and the gap widened year by year. In conjunction with Table 2, we can found that pension benefits only in Guangzhou and Zhuhai are in the treatment of moderate range, which in other cities are lower than the lower limit. This shows that the level of protection of UREI in Guangdong Province is generally low, and pensions issued cannot meet the basic living needs of elderly residents.

\subsection{Analysis of the Financial Burden at a Moderate Level of Pension}

Through the measurement of the basic living needs of urban and rural residents in Guangdong Province, it was found that the UREI benefits in Guangdong Province could not guarantee the basic living needs of the elderly residents, or even meet the food needs of the elderly residents. Increasing treatment is the trend, but it cannot be increased blindly. We must consider whether the government can afford the increased financial subsidies. As shown in Table 5, it is assumed that in the absence of central financial transfer payments, it is estimated whether the province's financial resources can support the improvement of UREI benefits. From 2014 to 2017, the number of people enjoying UREI benefit increased year by year. Financial burden caused by the lower limit of modest treatment was from 233.54 billion yuan in 2014 to 431 billion yuan in 2017, and which caused by the upper limit of modest treatment was from 504.90 billion yuan to 940.50 billion yuan. The province's fiscal revenue is also increasing year by year. The fiscal burden coefficient is defined as the fiscal burden scale/fiscal revenue. It can be seen that from 2014 to 2016, the fiscal burden coefficient continued to increase, and the growth rate in 2017 tended to slow down.

On the whole, the financial burden coefficient is small at the lower limit of modest treatment, and the province's fiscal revenue is able to support the increase of UREI benefits to a level that meets the food needs of elderly residents. However, if the benefits are increased to meet the food, clothing and housing needs of elderly residents, in terms of the financial strength of Guangdong Province alone, it will be more difficult and requires the support of the central government.

\section{Suggestions}

Urban and rural residents' endowment insurance is a major livelihood project

Table 5. Fiscal burden caused by UREI in Guangdong Province, 2014-2017.

\begin{tabular}{ccccccc}
\hline Years & $\begin{array}{c}\text { Number of recipients } \\
(10 \text { thousand })\end{array}$ & $\begin{array}{c}\text { Fiscal burden scale at the } \\
\text { lower limit (100 million) })\end{array}$ & $\begin{array}{c}\text { Fiscal burden scale at the } \\
\text { upper limit (100 million })\end{array}$ & $\begin{array}{c}\text { Fiscal revenue } \\
(100 \text { million })\end{array}$ & $\begin{array}{c}\text { The lower } \\
\text { limit/financial revenue }\end{array}$ & $\begin{array}{c}\text { The upper } \\
\text { limit/financial revenue }\end{array}$ \\
\hline 2014 & 773.32 & 233.54 & 504.90 & 8060.06 & $2.90 \%$ & $6.26 \%$ \\
2015 & 842.89 & 318.95 & 761.21 & 9364.76 & $3.41 \%$ & $8.13 \%$ \\
2016 & 893.08 & 391.70 & 940.50 & $10,390.33$ & $3.77 \%$ & $9.05 \%$ \\
2017 & 958.00 & 431.00 & 1043.17 & $11,315.21$ & $3.81 \%$ & $9.22 \%$ \\
\hline
\end{tabular}

Note: Calculated based on the relevant data of Guangdong Provincial Human Resources and Social Affairs Department, Finance Department and Table 4. 
with complex and long-term characteristics. For the time being, the treatment of UREI in Guangdong Province is relatively low, which cannot guarantee the normal life of elderly residents. As a public product, the implementation and development of UREI cannot be separated from government financial support. And finance has the ability to support pension benefits to a moderate level. Based on the analysis above, the following suggestions are proposed.

\subsection{Increase Fiscal Investment}

The policy objective of the UREI is to "basic guarantee", that is, to meet people's basic living needs. Through the above empirical analysis, it is found that in addition to Guangzhou and Zhuhai, the pension treatment of other cities in Guangdong Province cannot meet the aged' need for food consumption. Improving UREI benefits requires increased financial input and a reasonable division of fiscal subsidy responsibilities at all levels, including two aspects: one is the basic pension standard, and the other is the individual contribution subsidy standard. At present, provincial finance provides a certain percentage of financial subsidies only based on the minimum standards stipulated in the "Implementation Measures". The funds required to increase the basic pension and personal contribution subsidies are borne by the cities themselves, which undoubtedly increases the city and county finances burden. In particular, the cities with relatively backward economic development in the eastern, western and northern regions of Guangdong have weak fiscal budgets at the city and county levels, and are unable to afford the funds required to increase the UREI benefits. According to the rough calculations above, it is found that in terms of the province's financial resources, there is room for improvement in the level of old-age insurance benefits. Therefore, to improve UREI benefits, it is necessary to increase provincial financial investment and reasonably divide the financial responsibility of province, city, and county.

\subsection{Establishing a Normal Adjustment Mechanism for Basic Pensions}

The basic pension constitutes an important part of the UREI benefits. The economy is developing, prices are rising, and people's consumption expenditures are increasing. If the basic pension lacks a reasonable growth mechanism, the protection of UREI is bound to be weakened. Since 2013, Guangdong Province has repeatedly adjusted the basic old-age pension standards, but each time it increased by 5 or 10 yuan. The adjustment was relatively low and lacked a scientific basis, which is bound to weaken the effectiveness of UREI. Human Resources and Social Ministry and the Ministry of Finance in March 2018 jointly issued "on the establishment of urban and rural residents basic old-age insurance benefits and determine the basic pension normal adjustment mechanism of guidance" (Human Resources and Social hair [2018] No. 21), made it clear to co-ordinate considering the adjustment of other social security standards such as urban and 
rural residents' income growth, price changes, and basic pension insurance for employees, a national minimum pension adjustment plan for urban and rural residents was proposed in a timely manner. Establishing a normal adjustment mechanism for basic pensions is a trend of national policy. The Guangdong Provincial Government should refer to the national basic pension standards, combine the income of urban and rural residents, the price level, the adjustment of basic pension insurance for employees, and its own financial strength to establish a scientific and reasonable Basic pension adjustment mechanism. Before establishing a normal adjustment mechanism for basic pensions, it is recommended that the standard of basic pensions be raised to a level that meets the food needs of elderly residents, to ensure that participating residents share the fruits of economic and social development, and promote the healthy development of the basic pension insurance system for urban and rural residents.

\subsection{Establishing a Dynamic Adjustment Mechanism for Payment Subsidies}

According to the "Implementation Measures", public finance provide for a fixed subsidy for the contributions of insured personnel. If participant choose to pay at a level of 120 yuan to 360 yuan per year, the fiscal should give a subsidy of not less than 30 yuan per year, and if choosing a level of 480 yuan or more to pay, financial subsidy cannot be less than 60 yuan. This has led to the consequences of "reverse incentives". In actual situations, no matter whether the insured person chooses to pay 120 yuan, 240 yuan, or 360 yuan, he will receive a subsidy of 30 yuan, then people will be bound to tend to choose low-grade payment standards. Guangzhou government has streamlined payment levels and raised payment standards based on provincial regulations, but it has also adopted a fixed subsidy method. Residents in Guangzhou can choose seven payment grades, and the ratio of the financial subsidy to the payment amount is $1.5,1.17,1,0.86,0.78$, 0.68 , and 0.62 [19], which is equivalent to choosing a higher payment grade and obtaining less financial subsidies. In terms of payment subsidy, the practice of Zhuhai that changed the fixed subsidy to a proportional subsidy has important significance. At present, Zhuhai government provides financial subsidies to insureds according to $65 \%$ of the individual payment amount [20]. The government can reasonably determine the payment subsidy ratio based on the payment level selected by individuals and their affordability, which can people to choose higher-level payment standards to enrich their personal account funds.

\subsection{Change the Regional “One Size Fits All” Subsidy}

Guangdong Province is a large financial province in China with strong economic strength. However, it has been many years since the imbalance in economic development in various regions of the province, and the fiscal revenue gap between prefecture-level cities is very large. The financial revenue of Guangzhou and Shenzhen has been far ahead, and the two cities of Foshan and Dongguan have 
followed closely behind, but compared with the financial revenue of the previous two cities, there is still a large gap. The fiscal revenue rankings of other cities in the Pearl River Delta region vary greatly each year, but the fiscal revenues of Zhongshan, Jiangmen, and Zhaoqing are basically at the bottom. Moreover, the fiscal revenue of has been lower than some cities in eastern, western, and northern region of Guangdong Province in recent years. At present, the financial subsidies for the maintenance of old-age pensions in the urban and rural areas of the Pearl River Delta region are all borne by the city and county finances, and the provincial finance does not provide any support. This "one-size-fits-all" subsidy method ignores the fact that the economic development of the cities in the Pearl River Delta region is uneven and the fiscal revenue gap is large. The differences in the financial strength of the cities in the Pearl River Delta have resulted in differences in the treatment of UREI. This inequity will cause people to experience psychological gaps, and the "one-size-fits-all" financial subsidy method will undoubtedly deepen the institutional defects. To change the "one-size-fits-all" subsidy policy, that is, to change the pattern of differentiating financial subsidies by geographical location, different subsidy policies can be formulated according to the level of economic development, the status of fiscal revenue, the number of participants, and the degree of population aging. In the future, by gradually increasing the overall level of the basic pension insurance fund for urban and rural residents, within the scope of the overall planning level, measures such as a unified system framework, unified payment grades and standards, and unified payment standards will be used to ensure that urban and rural residents enjoy relatively fair basic pension insurance rights.

\section{Conclusions}

In the context of the basic realization of full coverage of endowment insurance, how to improve the level of protection is a hot issue that all sectors of society are concerned about. First of all, this paper analyzes the financial subsidy policy and actual treatment level of UREI in Guangdong Province, and finds that there are obvious differences in pension benefits in various regions of Guangdong Province. Secondly, based on the perspective of the basic living needs of elderly residents, this paper establishes a model to measure the appropriate treatment interval of UREI in Guangdong, and assesses the scale of financial burden. Studies show that the level of old-age treatment in most prefecture-level cities in Guangdong Province is below the lower limit of the moderate treatment interval and cannot meet the basic living needs of elderly residents. Guangdong's finance has the ability to raise the basic pension to the lower limit of the moderate treatment interval, but if it is to raise the basic pension to the upper limit of the moderate treatment interval, it needs the support of the central government. It is possible to consider adjusting the basic pension to the middle value of the moderate treatment interval.

This article proposes to improve the level of endowment insurance protection 
in Guangdong from the following four aspects: increasing financial input, establishing a normal adjustment mechanism for basic pensions, establishing a dynamic adjustment mechanism for payment subsidies, and changing regional "one-size-fits-all" subsidies. Among them, the establishment of a normal adjustment mechanism for basic pensions is the key to achieving the "basic guarantee" goal. The adjustment of the basic pension should provide a higher level of protection for the elderly residents without losing economic efficiency. In the long run, the establishment of a scientific adjustment mechanism can appropriately reduce the financial burden. In addition, the adjustment range and timing of the basic pension should be stable to maintain the sustainability of the system, as well as people's trust and support for the system.

\section{Conflicts of Interest}

The author declares no conflicts of interest regarding the publication of this paper.

\section{References}

[1] Department of Human Resources and Social Security of Guangdong Province (2018) The Minimum Standard of Basic Old-Age Insurance for Urban and Rural Residents in Guangdong Province Has Been Raised to 148 Yuan per Person per Month. http://www.gdhrss.gov.cn/gzdt/14329.jhtml

[2] Li, X.M., Yao, C.L. and Duan, M.Z. (2018) Effectiveness Test of Financial Subsidy Policy for Urban and Rural Residents' Basic Endowment Insurance. Finance and Accounting Monthly, 22, 149-156.

[3] Wang, L.J. and Ye, X.G. (2015) Research on the Basic Pension Adjustment Plan for Urban and Rural Residents under Demand Orientation. Journal of Xi an Jiaotong University, 5, 86-92.

[4] Liu, Z.H., Li, L.Y. and Peng, M.Y. (2016) Research on the Level of Urban and Rural Residential Security from the Perspective of Supply and Demand Balance-Taking Changsha City as an Example. Journal of Hunan University, 4, 119-125.

[5] Bian, S., Sun, Y.N. and Li, Y.A. (2017) Research on the Moderate Level of Urban and Rural Residents' Pensions from the Perspective of "Basic Security". Heilongjiang Social Science, 3, 75-83.

[6] Jing, P., Chen, M.J. and Hu, Q.M. (2018) Moderate Treatment and Financial Burden of Basic Endowment Insurance for Urban and Rural Residents. Financial Research, 10, 66-78.

[7] Huan, L. (2015) Evaluation and Reflection on the Basic Endowment Insurance Guarantee Level of Urban and Rural Residents: Based on the Perspective of Pension Replacement Rate. Population and Economy, 5, 91-99.

[8] Shen, Y. (2015) Research on the Moderate Level of Social Endowment Insurance for Chinese Urban and Rural Residents-Measurement and Comparison Based on the Need for "Living Fairness". Western Forum, 2, 47-53.

[9] Shang, C.F. (2004) Fiscal Reflections on the Rural Endowment Insurance System. Journal of Nanjing University, 5, 113-118.

[10] Li, C.Y. and Yang, J.F. (2008) On the Government's Financial Responsibility in the Rural Social Endowment Insurance System. Journal of Huazhong Agricultural Uni- 
versity, 5, 10-14.

[11] Long, M.J. (2009) On Government Financial Responsibility in Rural Social Endowment Insurance: An Empirical Analysis Based on Panel Data of Provinces and Cities in China from 1999 to 2003. Insurance Research, 5, 64-68.

[12] Gong, X.X., Cui, H.T. and Wang, Y. (2015) Financial Support for Sustainable Development of Rural Social Endowment Insurance System: Foreign Experience and Its Enlightenment. Comparison of Economic and Social Systems, 2, 44-52.

[13] Yang, B. (2016) Regional Differences in Government Financial Responsibility and Burden of Endowment Insurance for Urban and Rural Residents. Western Forum, 1, 102-108.

[14] Zhu, H.Y. (2014) Financial Burden and Sharing of Endowment Insurance for Urban and Rural Residents in Local Governments: Based on a Study in Wenzhou, Zhejiang Province. China Insurance and Social Security Research Center of Peking University, Beijing, 163-179.

[15] Huang, L., Luo, F. and Liu, H.M. (2014) Research on Government Subsidies for Social Endowment Insurance for Urban and Rural Residents: Based on Empirical Research in Guangdong Province. Population and Economy, 3, 110-116.

[16] Li, Q. and Li, Y. (2016) Research on Public Finance Supporting the Basic Endowment Insurance System for Urban and Rural Residents: A Case Study of Wuling Mountain Area, Hunan. Rural Economy and Science and Technology, 15, 215-217.

[17] Ministry of Human Resources and Social Security (2018) Relevant Person in Charge of Ministry of Human Resources and Social Security Answered Reporters' Questions on the "Guiding Opinions on Establishing the Basic Endowment Insurance Benefits for Urban and Rural Residents and Normal Adjustment Mechanism of Basic Pension".

http://www.mohrss.gov.cn/SYrlzyhshbzb/dongtaixinwen/buneiyaowen/201803/t201 80329_291012.html

[18] Mu, H.Z. (2016) Research on the Moderate Level of Social Security. Economic Research, No. 2, 56-63.

[19] Guangzhou Municipal People's Government (2014) Notice of the General Office of the People's Government of Guangzhou Municipality on Printing and Distributing the Implementation Measures for the Basic Endowment Insurance for Urban and Rural Residents in Guangzhou. http://www.gz.gov.cn

[20] Zhuhai Municipal People's Government (2014) Notice of Zhuhai Municipal People's Government on Printing and Distributing the Implementation Measures for the Basic Endowment Insurance for Urban and Rural Residents of Zhuhai. http://zwgk.gd.gov.cn/006988427/201409/t20140917_547531.html 